\title{
Relationships between Multidimensional Health Locus of Control and Low Back Pain: A Mini-Review
}

\author{
Jeremy Fletcher ${ }^{1 *}$ and Marjorie Scaffa ${ }^{2}$ \\ ${ }^{1}$ Department of Physical Therapy, University of South Alabama, USA \\ ${ }^{2}$ College of Medicine, University of South Alabama, USA
}

Submission: March 05, 2018; Published: September 18, 2018

*Corresponding author: Jeremy Fletcher, PT, DPT, OCS, CSCS, Department of Physical Therapy, University of South Alabama, Mobile, Alabama, USA, Email: jfletcher@southalabama.edu

\begin{abstract}
The introduction of a psychologically-informed practice framework has spawned the need to better conceptualize inclusion of patient beliefs as well as emotional and behavioural responses to the pain experience into the practice of physical therapy. Health Locus of Control (HLOC), a multidimensional construct, is becoming an important variable in the management of patients with painful conditions. As physical therapist began to adopt psychologically-informed principles in practice, identifying potentially modifiable variables linked to health beliefs, may prove valuable for the amelioration of painful conditions. The purpose of this paper is to examine current literature describing the relationships between HLOC and patients with low back pain and other relevant health outcomes.
\end{abstract}

Keywords: Multidimensional health locus of control; Self-efficacy; Low back pain; Psychologically-informed

\section{Introduction}

Psychologically informed practice is becoming the prevalent clinical framework for physical therapists managing patients with chronic low back pain [1]. The introduction of a psychologicallyinformed practice framework spawned from the need to better conceptualize inclusion of patient beliefs as well as emotional and behavioural responses to the pain experience into the practice of physical therapy. Within this framework, the physical therapist seeks to identify "yellow flag" risk factors for poor outcome and provide intervention. Conceptually, this model is a secondary prevention effort aimed at distinguishing modifiable and non-modifiable psychosocial risk factors for targeted intervention, while decreasing the likelihood of chronicity. Interventions may include medical management (pharmacology and psychotherapy), as well as specialized rehabilitation [2].

Early identification tools have been developed for patients with chronic low back pain and shown to be useful to identify patients who will present with higher levels of disability, pain, or fear of movement over a 12-month period [3]. More recently, the Optimal Screening for Prediction of Referral and Outcome-Yellow Flag (OSPRO-YF) was developed to allow for multidimensional yellow flag assessment in physical therapy settings [4]. The OSPRO-YF development included 3 domains of pain-associated psychological distress: negative mood, fear avoidance, and positive affect/coping. The tool is comprehensive including 11 psychological constructs that have been demonstrated to impact patient outcomes; however, an exhaustive systematic review of the literature was not performed prior to tool development. This article will present a rationale for including Health Locus of Control as an additional psychological construct in the identification of yellow flags.

\section{Health Locus of Control}

The origin of the concept of health locus of control (HLOC) stems from social learning theory. According to social learning theory, personality represents an interaction of the individual with his or her environment where the individual's behaviour is a function of expectancy and reinforcement value. Reinforcement acts to strengthen expectancy that a behaviour or event will be followed by that reinforcement in the future. The effect of the reinforcement, and to some degree the probability of the behaviour occurring in the future, depends on whether or not the individual perceives the reward as a result of his or her own behaviour. This is referred to as an internal locus of control. However, an individual may perceive the effect of the reinforcement was a result of chance, luck, or powerful others. This is referred to as an external locus of control [5].

Health Locus of Control (HLOC) refers to the extent to which individuals attribute their health to their own actions or to circumstances outside of their control [6]. Health locus of control can be viewed as a multidimensional construct, with three relatively independent dimensions. These include: 
(1) Internal, or the responsibilities for one's health is attributed to oneself and to the action one takes,

(2) External-powerful others, or the responsibility of one's health is assigned to other people (medical professionals, loved ones), and

(3) External-chance, or the responsibility for one's health is believed to depend on uncontrollable factors (good or bad, luck/fate) [7].

HLOC is not an all or nothing phenomenon, rather it is expressed along a continuum and can be measured. The Multidimensional Health Locus of Control Scale (MHLC) is an 18 item self report questionnaire that assesses the three dimensions of HLOC: internal, powerful others, and chance [8].

Persons with a strong internal HLOC are more likely to engage in health-related behaviours and thereby experience better physical and mental wellbeing than persons with an external HLOC [9]. In addition, scores on the internal HLOC scale are positively correlated with life satisfaction, informationseeking behaviours, adherence to health recommendations, and desire for control of the healthcare process [6].

According to Wallston \& Wallston [6], scores on the Powerful Others (i.e., health care providers) HLOC scale were positively correlated with information-seeking and adherence to treatment recommendations, but negatively correlated with desire for control over the healthcare process. Chance HLOC scores were found to be positively correlated with level of depression [5], and report of physical symptoms, and negatively correlated with desire for control over the healthcare process. Relationships between internal locus of control and health outcomes have been studied in various population. For example, high health internal locus of control, along with high self-efficacy are useful cognitive factors to facilitate recovery in athletes with anterior cruciate ligament injury [10]. Health-related internal locus of control has also been found to facilitate positive health behaviour change in cancer survivors [11]. Although external health locus of control has been found to negatively impact health outcomes, findings are inconsistent [7]. In addition, HLOC was found to be a predictor of psychiatric comorbidities in a chronic pain population. In this study, persons with a chance HLOC had significantly higher depression scores than persons with an internal HLOC (Wong \& Anitescu, 2016). Perceived personal lack of control in managing pain effectively can lead to feelings of hopelessness and helplessness, which are hallmarks of depression.

Health locus of control appears to be somewhat malleable. A randomized, controlled study by Rybarczyk, DeMarco, DeLaCruz, Lapidos, \& Fortner [12] demonstrated the effectiveness of a mind-body wellness intervention to modify HLOC beliefs (from a more external orientation to a more internal orientation) with a group of adults with chronic health conditions.

Related to the concept of HLOC is self-efficacy. Self-efficacy is already included in the OSPRO-YF and refers to the individual's belief in his or her ability to effectively enact a specific behaviour or perform a particular skill. Higher self-efficacy enhances the likelihood that the behaviour or skill will occur [13]. Therefore, persons are more likely to engage in health behaviours if they perceive a positive outcome to be within their control (HLOC), and if they perceive themselves as being capable of performing the behaviour (self-efficacy). Evaluating these characteristics and utilizing strategies to increase internal HLOC and healthrelated self-efficacy in our patients may enhance adherence to therapist recommendations and improve outcomes.

\section{Health Locus of Control and Low Back Pain}

A recent prospective, cross-sectional study examined the relationship between depression and health locus of control (HLOC) in adult patients with persistent pain (Wong \& Anitescu, 2016). 131 patients with chronic pain were administered the Multidimensional Health Locus of Control Scale (MHLC), Beck Anxiety Inventory (BAI), Zung Self-Rating Depression Scale (Zung), Quality of Life Scale, and Pain Disability Index, and Numeric Rating Scale (NRS). Results revealed that patients with an internal locus of control were less depressed compared to patients with a chance, or external locus of control. The authors suggest that healthcare professionals and clinicians could contribute to the decrease of psychiatric comorbidities in the chronic pain population by influencing patients' health locus of control. These findings may indicate another potentially modifiable variable to include in the screening for psychosocial risk factors by physical therapists. Additionally, HLOC and selfefficacy have demonstrated value as predictors of physical and mental health in patients completing a two-week spine rehabilitation program [14]. Higher internal locus of control and lower doctor health locus of control, and higher selfefficacy at baseline predicted higher lift scores one month after intervention. Higher self-efficacy also predicted better physical functioning. Applications of these findings include assessing the cost-effectiveness of using screening measures to predict outcome [14].

\section{Complementary and Integrative Health}

According to the National Center for Complementary and Integrative Health, back pain is the number one disease/condition for which complementary health approaches are most frequently used (NCCIH, 2017). Interestingly, the top five conditions (back pain, neck pain, joint pain or stiffness, cardiovascular conditions, and arthritis/gout/lupus/fibromyalgia) are all conditions frequently encountered by physical therapist. Patients are also engaging in many passive and active forms of complementary and integrative care. Passive modalities, defined as physical modalities or devices that do not require the active participation of patients (including rest) (Hainan, et al. 2015), include chiropractic or osteopathic manipulation and massage. Active modalities, defined as interventions that require patient participation (Hainan et al. 2015), include deep breathing, yoga, Tai chi, Qi Gong, progressive muscle relaxation, guided imagery, and meditation (NCCIH, 2017). 


\section{Intervention}

As physical therapists adopt a psychologically-informed approach to patient management, complementary and integrative health strategies, both active and passive, are also being adopted (PT in Motion, 2014). As mentioned previously, the construct of internal locus control is predicated by the belief that one's health is attributed to oneself and to the action one takes, while external locus of control associates one's health to the actions of others. Given the increased utilization of complementary and integrative practices in physical therapy, and our understanding of how HLOC affects health outcomes, HLOC may be an important modifiable variable, especially in those populations who may better align with an active vs. passive approaches to management. For example, Cramer and colleagues examined 2,486 patients who attended a 14day integrative medicine inpatient program in Germany [15]. Intervention included exercise (yoga, qigong, nordic walking), meditative movement, and stress management (progressive muscle relaxation, mindfulness meditation, breathing exercises and guided imagery). Patients were encouraged to continue these practices beyond discharge [16-18]. Exercise self-efficacy, stage of change, and health locus of control (internal, externalsocial, external-fatalistic) were measured at 3,6 , and 12 months. Although no one single construct predicted changes in behaviour, HLOC was associated with changes from admission to 3,6 , and 12-month follow-up for practice frequency of relaxation techniques and with changes from admission to 3-month followup for aerobic exercise [19-22].

\section{Conclusion}

Considering the positive associations between HLOC and health outcomes, physical therapists may benefit from the assessment of a patient's current perception of control and choose to either a) create intervention strategies that align with the patient's current locus of control, or b) design individual behaviour change programs to encourage a more internal locus of control [23,24]. Physical therapist may be able to better tailor psychologically-informed approaches to patient management by assessing health beliefs including self-efficacy and health locus of control, thereby increasing patient adherence, patient engagement, and health outcomes [25-27]. Future studies could also examine relationships between health locus of control, selfefficacy, and passive vs. active interventions.

\section{References}

1. Main CJ, George SZ (2011) Psychologically Informed Practice for Management of Low Back Pain: Future Directions in Practice and Research. Phys Ther 91(5): 820-824.

2. Nicholas MK, George SZ (2011) Psychologically informed interventions for low back pain: an update for physical therapists. Phys Ther 91(5): 765-776.

3. Pagé I, Abboud J, O Shaughnessy J, Laurencelle L, Descarreaux M (2015) Chronic low back pain clinicaloutcomes present higher associations with the STarT Back Screening Tool than with physiologic measures: a 12-month cohort study. BMC Musculoskelet Disord 16: 201.
4. Lentz TA, Beneciuk JM, Bialosky JE, Zeppieri G, Dai Y, et al. (2016) Development of a yellow flag assessment tool for orthopaedic physical therapists: results from the optimal screening for prediction of referral and outcome (OSPRO) cohort. J Orthop Sports Phys Ther 46(5): 327343.

5. Presson PK, Benassi VA (1996) Locus of control orientation and depressive symptomatology: A meta-analysis. Journal of Social Behavior and Personality 11(1): 201-212.

6. Wallston KA, Wallston BS (1982) Who is responsible for your health: The construct of health locus of control. In: Sanders G, Suls J (Eds.), Social psychology of health and illness. Lawrence Erlbaum \& Associates, Hillsdale, New Jersey, USA, pp. 65-95.

7. Janowski K, Kurpas D, Kusz J, Mroczek B, Jedynak T (2013) Healthrelated behavior, profile of health locus of control and acceptance of illness in patients suffering from chronic somatic diseases. PLoS ONE 8(5).

8. Wallston KA, Wallston BS, De Vellis R (1978) Development of the multidimensional health locus of control (MHLC) scales. Health Educ Monogr 6(2): 160-170.

9. Pucheu S, Consoli SM, D’Auzac C, Français P, Issad B (2004) Do health causal attributions and coping strategies act as moderators of quality of life in peritoneal dialysis patients? Journal of Psychosomatic Research 56(3): 317-322.

10. Christino MA, Fleming BC, Machan JT, Shalvoy RM (2016) Psychological factors associated with anterior cruciate ligament reconstruction recovery. Orthop J Sports Med 4(3): 2325967116638341.

11. Park CL, Gaffey AE (2007) Relationships between psychosocial factors and health behavior change in cancer survivors: an integrative review. Ann Behav Med 34(2): 115-134.

12. Rybarczyk B, DeMarco G, DeLaCruz M, Lapidos S, Fortner B (2001) A classroom mind/body wellness intervention for older adults with chronic illness: Comparing immediate and 1-year benefits. Behav Med 27(1): 15-27.

13. Bandura A (1997) Self-efficacy: The exercise of control. Freeman/ Times Books/Henry Holt \& Co, New York, USA.

14. Keedy NH, Keffala VJ, Altmaier EM, Chen JJ (2014) Health locus of control and self-efficacy predict back pain rehabilitation outcomes. Iowa Orthop J 34: 158-165.

15. Cramer H, Lauche R, Moebus S, Michalsen A, Langhorst J, et al. (2014) Predictors of health behavior change after an integrative medicine inpatient program. Int J Behav Med 21(5): 775-783.

16. Beinart NA, Goodchild CE, Weinman JA, Ayis S, Godfrey EL (2013) Individual and intervention-related factors associated with adherence to home exercise in chronic low back pain: A systematic review. Spine J 13(12): 1940-1950.

17. Macrodimitris SD, Endler NS (2001) Coping, control and adjustment in Type 2 diabetes. Health Psychology 20(3): 208-216.

18. Theofilou P (2012) Quality of life and mental health in hemodialysis and peritoneal dialysis patients: the role of health beliefs. Int Urol Nephrol 44(1): 245-253.

19. World Health Organization (2003) Adherence to long-term therapiesEvidence for action.

20.Alexanders J, Anderson A, Henderson S (2015) Musculoskeletal physiotherapists' use of psychological interventions: a systematic review of therapists' perceptions and practice. Physiotherapy 101(2): 95-102.

21. Härkäpää K, Järvikoski A, Mellin G, Hurri H, Luoma J (1991) Health locus of control beliefs and psychological distress as predictors for treatment outcome in low-back pain patients: results of a 3-month follow-up of a controlled intervention study. Pain 46(1): 35-41. 
22. Nicholas MK, Linton SJ, Watson PJ, Main CJ, Decade of the Flags Working Group (2011) Early identification and management of psychological risk factors ("yellow flags") in patients with low back pain: a reappraisal. Phys Ther 91(5): 737-753.

23. Ono R, Higashi T, Suzukamo Y, Konno S, Takahashi O, et al. (2008) Higher internality of health locus of control is associated with the use of complementary and alternative medicine providers among patients seeking care for acute low-back pain. Clin J Pain 24(8): 725-730.

24. Slade SC, Molloy E, Keating JL (2009) People with non-specific chronic low back pain who have participated in exercise programs have preferences about exercise: a qualitative study. Aust J Physiother 55(2): 115-121.

25. Wallston KA (2005) The validity of the multidimensional health locus of control scales. J Health Psychol 10(5): 623-631.

26. NCCIH (2018) Health.

27. Michele W (2018) Integrative Medicine.
This work is licensed under Creative

Commons Attribution 4.0 License

DOI: 10.19080/JYP.2018.06.555683

\section{Your next submission with Juniper Publishers will reach you the below assets}

- Quality Editorial service

- Swift Peer Review

- Reprints availability

- E-prints Service

- Manuscript Podcast for convenient understanding

- Global attainment for your research

- Manuscript accessibility in different formats

( Pdf, E-pub, Full Text, Audio)

- Unceasing customer service

Track the below URL for one-step submission

https://juniperpublishers.com/online-submission.php 